\title{
One Step Synthesis of Coumarinfrom Cinnamaldehyde via Cinnamic Acid Intermediate
}

\author{
Made Sudarma*, Siti Laili Zarwati and Made G Darmayanti \\ Department of Chemistry, University of Mataram, Indonesia

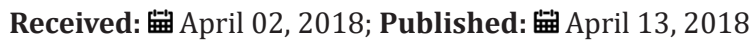 \\ *Corresponding author: Made Sudarma, Department of Chemistry, University of Mataram, Indonesia, Tel: 0370 646506; \\ Fax: 0370648508 ; Email: sud_arma@yahoo.co.id
}

\begin{abstract}
The purpose of this study was to develop an efficient method for the synthesis of pharmacologically interesting coumarin (1-benzopyran-2-one) from readily accessed natural products, in particular cinnamaldehyde. One step methodology for the synthesis of coumarin has been developed from cinnamaldehyde. A coumarin was synthesized smoothly via addition of chloro sulfonic acid to cinnamaldehyde. All the products have been confirmed by Thin Layer Chromatography and Gas Chromatography Mass Spectromatry analysis data.
\end{abstract}

Keywords: One step synthesis; Coumarin; Cinnamaldehyde; Chlorosulfonic acid

\section{Introduction}

Coumarin (1-benzopyran-2-one)is an organic compound, belonging to the class of benzopyrones, and is naturally found in many plants.It can be found in cinnamon bark. Coumarin has a wide range of applications such as, as perfumes, cosmetics, and industrial additives. Some of its derivatives have been used as aroma enhancers in tobaccos and certain alcoholic drinks. Moreover, a lot of coumarin compounds as medicinal candidates for drugs with strong pharmacological activity, low toxicity and side effects, fewer drug resistance, high bioavailability, broad spectrum, better curative effects, etc., to treat various types of diseases are being actively studied [1]. Coumarins also have been found to have multibiological activities such as anti-HIV, anti-tumor, anti-hypertension, anti-arrhythmia, anti-osteoporosis, pain relief, and preventing asthma and antisepsis [2]. While coumarins are only approved for a few remedial uses as pharmaceuticals, it may be noted that during a number of studies, they have also demonstrated some proof of numerous biological activities [3]. Coumarin is known to be moderately toxic to the liver and the kidneys, with an LD50 value of $275 \mathrm{mg} / \mathrm{kg}$.

This compound is metabolized differently in mice, rats and humans. Coumarin can be prepared by a number of name reactions with the Perkin reaction between salicylaldehyde and acetic anhydride being a popular example. The Pechmann condensation provides another route to coumarin and its derivatives; as does the Kostanecki acylation which can also be used to produce chromones [4]. An efficient annulation of phenolic acetates with acrylates in the presence of [Rh2(OAc) 4] as catalyst and formic acid as reducing agent provides high yield of coumarin derivatives via $\mathrm{C}-\mathrm{H}$ bond activation [5]. An efficient metal-free tandem acylation/cyclization of alkynoates with aldehydes enables the synthesis of 3-acyl-4arylcoumarins via addition of acyl radical to alkynes and a C-H bond fictionalization to form two new C-C bonds simultaneously [6]. Arylpropionic acid methyl esters having a MOM-protected hydroxy group at the ortho position underwent hydroarylation with various arylboronic acids in $\mathrm{MeOH}$ at ambient temperature in the presence of a catalytic amount of $\mathrm{CuOAc}$, resulting in the formation of 4-arylcoumarins in high yields [7].

\section{Experimental}

\section{Materials}

The material used included: cinnamon bark, dichloromethane, hexane, methanol, acetate anhydride, ethanol, sodium hydroxide pellet, hydrochloric acid, sodium hydrogen carbonate anhydrous, ethyl acetate, sodium carbonate anhydrous, chlorosulfonic acid, sulphuric acid, analytical thin layer chromatography, silica gel chromatography. 


\section{General procedure}

The dried of cinnamon bark was purchased from Suweta traditional market Lombok Barat Regency (250 g) were ground to very small size powder and extracted by maceration with dichloromethane $(2 \times 500 \mathrm{~mL})$ for 24 hours at room temperature and stored away from light. Concentration of solution of dichloromethane under reduced pressure by rotary evaporator gave the brownish cinnamon oil $(2.35 \mathrm{~g} ; 0.94 \%)$. The oil was analyzed by Thin Layer Chromatography (TLC) and Gas Chromatography and Mass Spectrometry (GC-MS). TLC analyses showed cinnamaldehydesampel $\mathrm{R}_{\mathrm{f}}$ 0.63(eluent, hexane:dichloromethane; 1:1). GC-MS showed cinnamaldehyde 74.13\%: M+.132, cal for $\mathrm{C}_{9} \mathrm{H}_{8} \mathrm{O}$, major fragments: $103\left(\mathrm{M}^{+} .-\mathrm{CO}\right), 77$ (benzene ring), and 51.

\section{Isolation of cinnamaldehyde}

The cinnamon oil extract $(2 \mathrm{~g})$ was subjected to silica gel column chromatography (eluent, hexane:dichloromethane; 1:1). Cinnamaldehyde (938mg, 46.91\%) was obtained from this separation and confirmed by TLC and GC-MS analysis (Figures 1 \& 2).

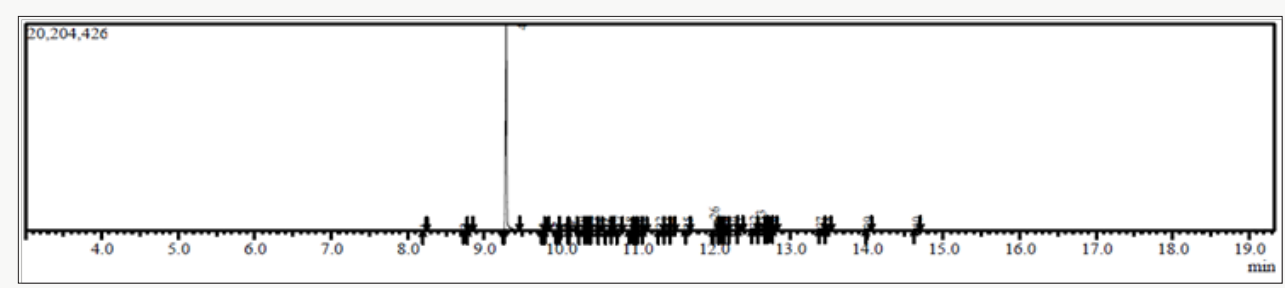

Figure 1.

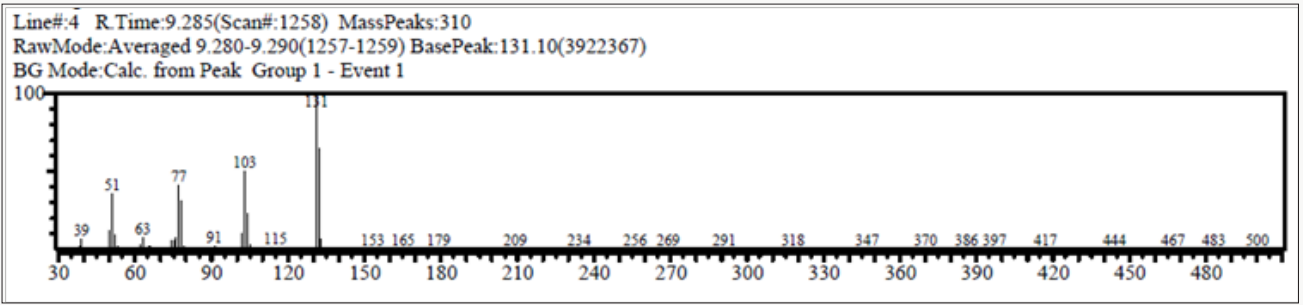

Figure 2.

\section{Synthesis of coumarin}

Thisreaction was conducted by adopting method from Sudarma. To stirred solution of cinnamaldehyde (1) (1003 mg, 7.8mmol) in dichloromethane $(20 \mathrm{~mL})$ was added chlorosulfuric acid $(2 \mathrm{~mL})$ drop by drop. The solution was stirred at room temperature for $30 \mathrm{~min}$ then refluxed for $15 \mathrm{~min}$. The solution was evaporated and water
(10mL) then added, basified to $\mathrm{pH} 8$ with $1 \mathrm{M}$ sodium hydroxide, then extracted with dichloromethane. The organic phase was dried and evaporated to dryness to give brown gum (685mg). TLC and GC-MS analysis showed coumarine (44.63\%).GC-MS: $\mathrm{M}^{+} .146$, cal for $\mathrm{C}_{9} \mathrm{H}_{6} \mathrm{O}_{2}$.Major fragments: 118 (base peak), and 65 (Figures 3 \& 4).

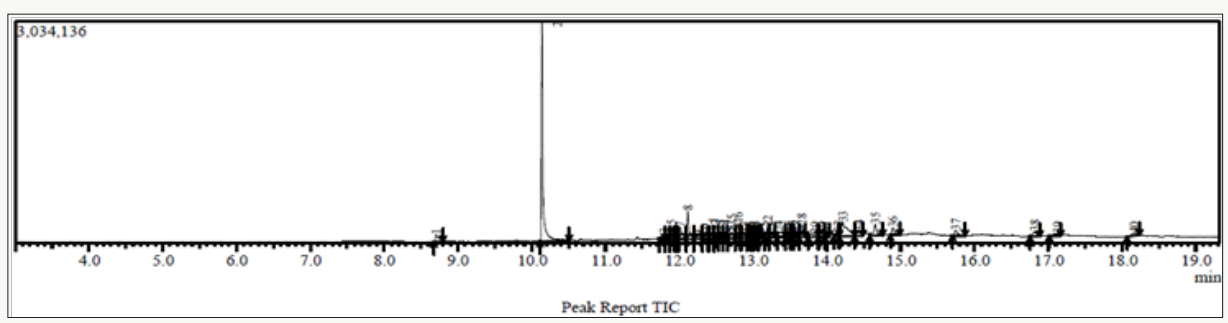

Figure 3.

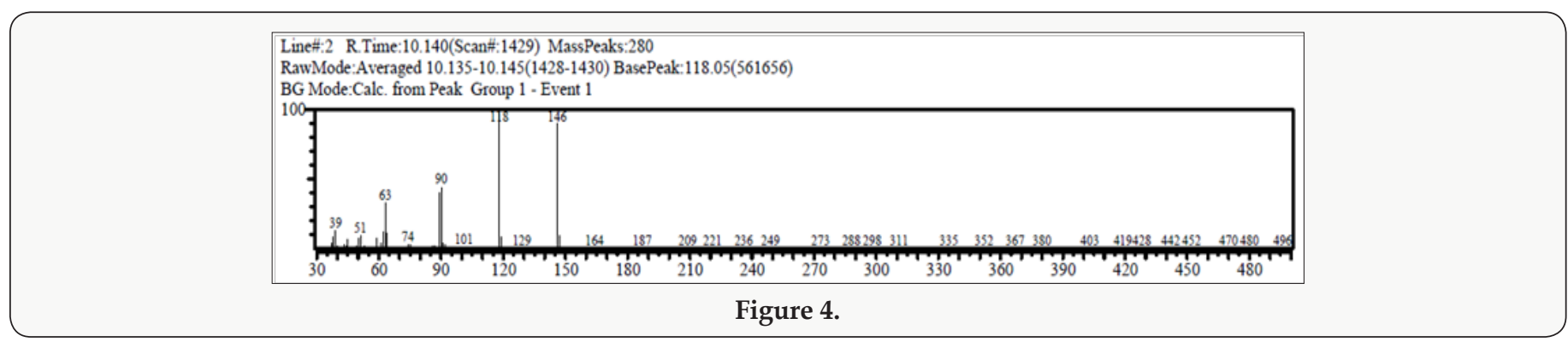

Citation: Made S, Siti L Z, Made G D. One Step Synthesis of Coumarinfrom Cinnamaldehyde via Cinnamic Acid Intermediate. Arc Org Inorg Chem Sci 2(4)- 2018. AOICS. MS.ID.000144. DOI: 10.32474/AOICS.2018.02.000144. 


\section{Results and Discussion}

In continuation of our work on transformation of readily accessed natural products such as eugenol and cinnamaldehyde, synthesis of coumarin via addition of chlrosulfonic acid or sulphuric acid to cinnamaldehyde was reported. This works involved isolation of cinnamaldehyde from bark of true cinnamon (Cinnamomumverum) and its transformation to coumarin. Cinnamaldehyde was extracted and isolated from cinnamon oil in good yield (75\%). Cinnamaldehydeis an organic compound with the formula $\mathrm{C}_{6} \mathrm{H}_{5} \mathrm{CH}=\mathrm{CHCHO}$ as predominately the trans (E) isomer. Occurring naturallyin the bark of cinnamon trees and other species of the genus Cinnamomum like camphor and cassia [8]. Synthesis of coumarin by addition of chlorosulfonic acid to cinnamaldehyde via oxidation reaction to cinnamic acid intermediate (Scheme 1). Simple coumarins are biogenetically derived from shikimic acid, via cinnamic acid [9]. Cinnamaldehyde is oxidized in vivo to cinnamicacid, which excrete in our urine [10]. These mean that on synthesis of coumarin from cinnamaldehyde presumably also via cinnamic acid as an intermediate and involved oxidation reaction. The mild oxidation of cinnamaldehyde should obviously yielded cinnamic acid.In the first step; one mol of water was added in the presence of an acidic catalyst ( $\mathrm{ClSO} \mathrm{H}$ ) to produce a hydrate. Subsequently, the hydrate was oxidized to the cinnamic acid formally by eliminating water. Cyclization ofcinnamic acid to coumarin was presumably initiated by addition of chlorosulfonic acid to its carbonyl (Scheme 2).

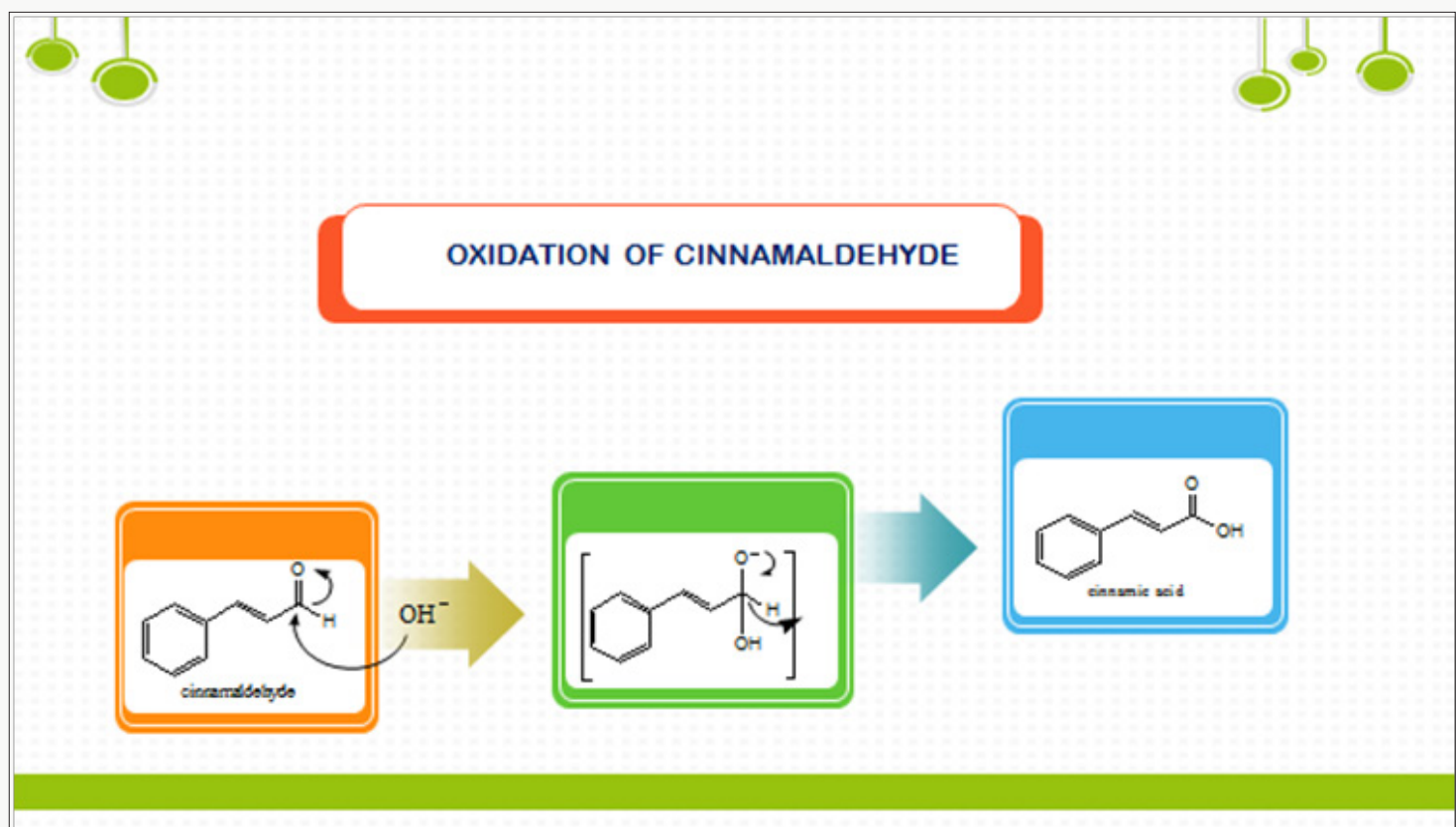

Scheme 1: Mechanism of cinnamic acid formation from cinnamaldehyde.

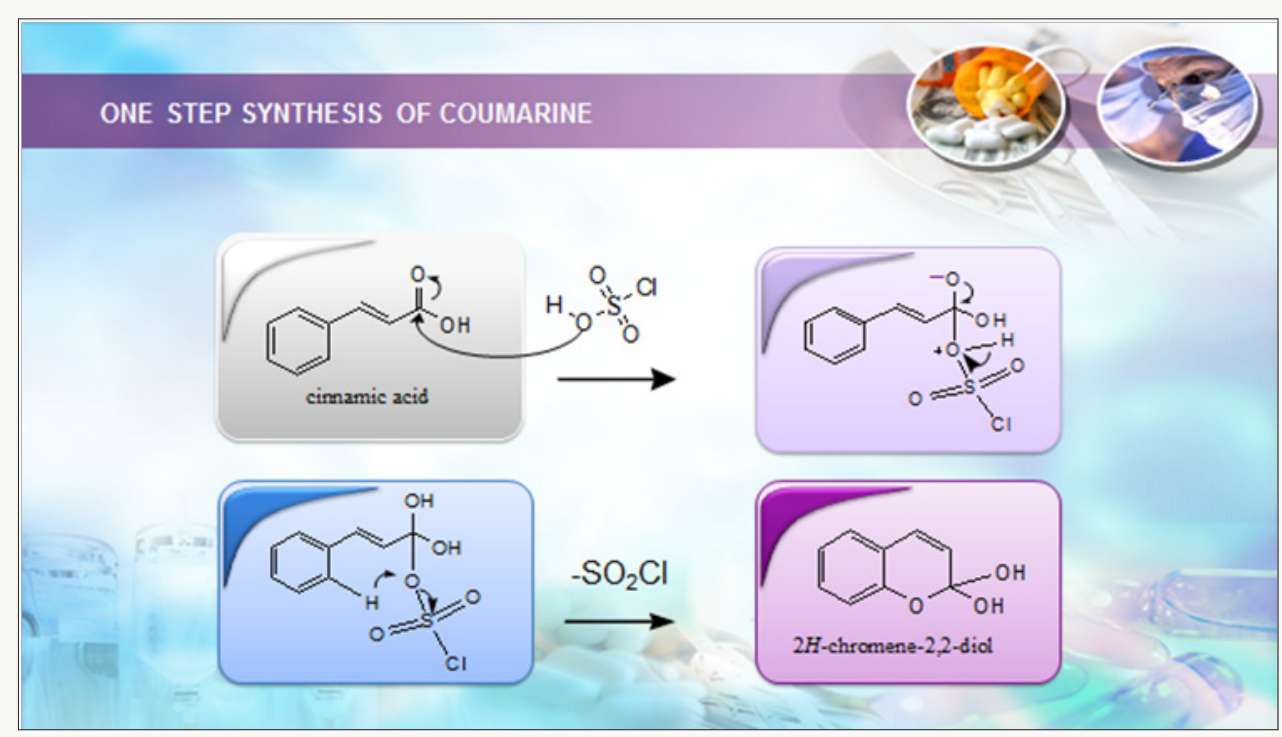

Scheme 2: Synthesis of coumarin from cinnamaldehyde via cinnamic acid. 


\section{Conclusion}

An efficient method using chlorosulfonic acid reagent was believed to be a suitable method for the synthesis ofcoumarin from cinnamaldehyde [11].

\section{Acknowledgement}

The authors thank Indonesian Ministry of Research, Technology, and Higher Education (KementerianRiset, Teknologi, danPendidikan Tinggi) through "HibahBerbasisKompetensi" for financial support.

\section{References}

1. Benefit from Cinnamon, everything you want to know about cinnamon.

2. Maria João Matos, Lourdes Santana, Eugenio Uriarte, Orlando A Abreu, Enrique Molina, et al. (2015) Coumarins -An Important Class of Phytochemicals. Agricultural and Biological Sciences.
3. Ray Sahelian MD (2016) Coumarin research studies.

4. Herbs2000.com

5. Coumarin from Wikipedia, the free encyclopedia.

6. SK Gadakh, S Dey, A Sudalai (2015) Synthesis of Coumarins. J Org Chem 80: $11544-11550$

7. X Mi, C Wang, M Huang, Y Wu (2015) Synthesis of Coumarins. J Org Chem 80: $148-155$.

8. Y Yamamoto, N Kirai (2008) Synthesis of Coumarins. Org Lett 10: 55135516.

9. Cinnamaldehyde, from Wikipedia, the free encyclopedia.

10. F Bourgaud, A Hehn, R Larbat, S Doerper, E Gontier, et al. (2006) Biosynthesis of coumarins in plants: A major pathway still to be unravelled for cytochrome P450 enzymes. Phytochem Rev 5(2-3): 293308.

11. IM Sudarma, E Yuanita, I W Suana (2013) Markovnikov addition of chlorosulfuric acid to eugenol isolated from clove oil. Indones J Chem 13(2): 181-184.

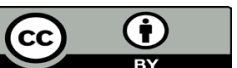

This work is licensed under Creative Commons Attribution 4.0 License

To Submit Your Article Click Here:

Submit Article

DOI: 10.32474/AOICS.2018.02.000144

\section{AOICS}

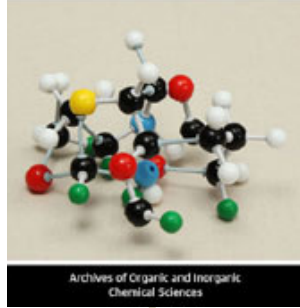

\section{Archives of Organic and Inorganic} Chemical Sciences

\section{Assets of Publishing with us}

- Global archiving of articles

- Immediate, unrestricted online access

- Rigorous Peer Review Process

- Authors Retain Copyrights

- Unique DOI for all articles 